\title{
The Use of Learning Strategies Among Learners of Spanish: an Empirical Study
}

\author{
Sergio Di Carlo \\ Universidad Nacional de Córdoba
}

Received: 6 January 2015 / Accepted: 14 August 2015

ISSN: 1697-7467

\begin{abstract}
This paper presents an empirical study focused on the language learning strategies used by 69 students of Spanish at college teaching centers. The objectives of this research were to identify and describe the types of language learning strategies used by the participants. A quantitative methodological profile was applied for this descriptive exploratory study. The data collection instrument was a Likert-type scale, used in other researches, which was adapted to Spanish. Data analysis was conducted using a descriptive statistical analysis. The results showed that social strategies seemed to be the ones most commonly used, followed by metacognitive and cognitive strategies. Affective and memory strategies proved to be the least used. Additionally, certain features about strategies use were observed, which could be linked to factors, such as gender and nationality, according to previous similar studies.
\end{abstract}

Keywords: Spanish as a second language, learning strategies, foreign language acquisition, factors.

\section{El uso de estrategias de aprendizaje en estudiantes de español: un estudio empírico}

RESUMEN: Este trabajo presenta un estudio empírico sobre las estrategias de aprendizaje de lenguas utilizadas por 69 estudiantes de español en centros universitarios. Los objetivos propuestos fueron la identificación y la descripción del uso de los tipos de estrategias de aprendizaje. Se aplicó un perfil metodológico cuantitativo con uso de estadística descriptiva. El instrumento de recolección de datos fue una adaptación de una escala tipo Likert usada en otras investigaciones. Los resultados mostraron que las estrategias sociales destacaron por ser las más utilizadas, seguidas de las metacognitivas y las cognitivas, mientras que las afectivas y las mnémicas resultaron ser las menos usadas. Asimismo, se observaron ciertos fenómenos en el uso de estrategias que podrían estar asociados a factores, tales como el sexo y la nacionalidad, según otros estudios han hipotetizado.

Palabras clave: español como segunda lengua, estrategias de aprendizaje, adquisición de lengua extranjera, factores.

\section{INTRODUCTION}

Geopolitical dynamics, advances in communications technology and market diversification are some of the factors that lead more people to learn a greater number of languages. In this context, strategic thinking in language learning becomes important. The educational intervention should aim to enable learners to mediate their own meaningful learning; that is, to be capable of 'learning to learn'. In other words, autonomous learning requires from 
students of foreign languages to take responsibility and control their own learning processes. Reaching autonomy in learning is extremely difficult to think of as an innate or spontaneous behavior. It is a skill that one acquires and develops over time as a result of personal experience or through formal, systematic and intentional learning.

Autonomy itself involves strategies that allow its development and consolidation. Knowledge and appropriate application of language learning strategies can make the learning process a linguistic and personal growth experience that can also be transferable to other areas of learning. However, to encourage the development of language learning strategies (LLS), it is first necessary to further study the nature of those strategies used by students. The contributions of this study would help teachers to know and to understand how the students of a second language learn, so they could help them to learn more effectively and with greater success through these processes, as well as enhancing appropriate strategies for each occasion.

To achieve this goal of creating strategic learners, strategic teachers are needed who have become aware of the complex cognitive and metacognitive processes that are mobilized to learn. Hence, serious work is required, either in training, teaching, or quality researches in this theoretical area. Autonomy in learning a second language is a recurring issue of discussion that has been gaining ever greater rise in research from 1990 on in the field of second languages teaching and learning. Although these studies have made great progress in the field of English language, very few have been conducted in the field of Spanish as L2, despite the relevant importance this language has gained in recent years worldwide: Spanish is the official language of twenty-one countries and it is the second most spoken language in the world by the number of native speakers with a number of near 395 million (Moreno \& Roth, 2007). Moreover, it is estimated that 450 million people speak Spanish as their mother tongue and as a second/ foreign language (Instituto Cervantes, 2006:32) and globally, nearly 18 million students are learning Spanish.

Although the Spanish language now occupies the second place as most studied foreign language in the world and its importance as an ideal vehicle to access the rich cultural heritage of the Spanish-speaking countries as well as a guarantee for contribution to multilingualism and multiculturalism is acknowledged, a large number of aspects of learning strategies in Spanish as a second language are still unknown.

Specific questions for this research were: What types of language learning strategies are used by students of Spanish as a second language? What types of language learning strategies are most and least common in those students? The objectives for this work were: to identify the types of learning strategies used by students of Spanish as a second language and to describe the frequency of use of learning strategies used by those students.

\section{ThEORETICAL BACKGROUND}

\subsection{Classification and theory on learning language strategies}

Oxford (1990) considers foreign language learning strategies as actions or specific skills that students use, often intentionally, to improve their skills in the mastery of language. From this definition, she distinguishes between various strategies that are part of the factorial 
structure of the Strategy Inventory for Language Learning (SILL) and provides one of the most complete classifications. Although the theory does not lack its critics, for example see Dörnyei (2005), even today it is regarded as one of the most-used classifications and her work has become indispensable in the field of language learning strategies. One of the latest taxonomies worth mentioning was proposed by Oxford (2011) through the Strategic SelfRegulation ( $\left.\mathrm{S}^{2} \mathrm{R}\right)$ Model of language learning which introduces the concept of metastrategies, a broad range of processes used to manage and control learning in general and the other three dimensions of learning strategies: cognitive, affective and sociocultural-interactive. In addition, tactics are also considered in the model, as specific manifestations of strategies or metastrategies under certain settings. In this sense, a wide and exhaustive list of examples of strategies, metastrategies and their respectful tactics is given by the author based on previous researches over the last two decades.

\subsection{Strategies, performance and gender}

Green and Oxford (1995) presented their study in which SILL was used in various geographical and cultural contexts. They came to the result that students with higher proficiency in foreign language use a greater number of strategies. Furthermore, the study shows a significant difference of use in favor of women over men, which is coincident with the revision conducted by Rahimi, Riazi and Saif (2008) and Griffiths (2003) about this issue. Griffiths (2003) worked with the same inventory and a sample of 348 English students in his doctoral thesis research, in which she came to the conclusion that higher-level students reported more frequent use of language learning strategies, whereas women showed a higher degree in frequency use.

\subsection{Degree of use and assessment tools}

Almost all quantitative studies related to the frequency of use of the latest learning strategies have been conducted using the Strategy Inventory for Language Learning. Roncel Vega (2002) published his research carried out between 1999 and 2002 in public schools at the secondary level in the province of Seville, with 650 participating students. He described the steps followed to estimate the psychometric parameters of his adapted SILL scale (adapted and translated into Spanish) and he had as result that the reliability of the scale was optimal and the outcomes were very similar to the original SILL's factors.

\section{Method}

\subsection{Participants}

This research was conducted in three Spanish teaching areas at two different universities in Córdoba, Argentina. The non-probabilistic sample consisted of $N=69$ students of Spanish as a second language (SL2) who were attending courses and classes. There was no distinction between proficiency levels or typology of courses (regular, individual, and intensive) when students were selected. 
The $78 \%$ of the sample consisted of students between 20 and 24 years old. Regarding gender, 23 males and 46 women from different nationalities participated: EE.UU. (32), China (13), Germany (12), Brazil (5) and other countries (7). The proficiency of the students in Spanish was quite diverse: in most cases, students already had some knowledge of Spanish, except a particular group of Chinese students. Note that the learning processes took place mostly in natural immersion settings. With regards to academic level, in almost all cases students were enrolled in college, both at undergraduate and graduate level, in their respective countries. They were taking Spanish courses through exchange programs. In the case of the group of Chinese students, most of them were starting to study Spanish in order to gain access to bachelor courses at universities in Córdoba.

\subsection{Approach}

In this project, I worked according to Oxford's (1990) classification of language learning strategies, with only one difference: compensation strategies were not considered as learning strategies, but rather as communication strategies, so they were not included in this study. One of the first authors who considered the difference between learning strategies and communication strategies was Selinker (1972), and some others followed his perspective, for example Tarone (1981) and more particularly, O'Malley and Chamot (1990:43) who claim that "communication strategies are an adaptation to the failure to realize a language production goal", but "learning strategies are attempts to develop linguistics and sociolinguistic competence in the target language." Despite the fact that there's an interdependence between communication strategies and learning strategies, Oxford's compensation strategies fit better as communication strategies rather than learning strategies, and this is why I chose to remove them from the inventory.

The study focused on the use of learning strategies of Spanish as a second language, according to this modified classification: memory, cognitive, metacognitive, affective and social.

This descriptive exploratory study was framed in a neo-positivist approach. The research was conducted under a quantitative profile in four phases, according to Corbetta (2007): (a) Research design: The phases followed a logical sequence; concepts were only operational; the psychological interaction between the researcher and the students was distant and neutral; the role of the studied subjects was passive. (b) Data collection: The research design was structured; the research instrument was uniform for all subjects; a data matrix was built; the nature of the data was objective. (c) Data analysis: The variable was the object of study; mathematical and statistical techniques were applied. (d) Outcomes: Data was presented in tables and graphs; generalizations over the sample were sought. It is worth mentioning that the production of results was complemented by some holistic interpretations and discussions on some strategies and categories.

\subsection{Data collection and organization}

The inventory was the only instrument used to collect data. The use of my own adaptation (in Spanish) of the original scale known as Strategy Inventory for Language Learning (SILL) Version 7.0 (Oxford, 1990:293-300) was the first step in this research, although it was modified in the sense that compensatory strategies were not considered as learning strate- 
gies. The Likert-type scale consisted of 44 items (44 strategies) in five different categories and numbered as follows: memory $(1,2,3,4,5,6,7,8,9)$, cognitive $(10,11,12,13,14$, $15,16,17,18,19,20,21,22,23)$, metacognitive $(24,25,26,27,28,29,30,31,32)$, affective $(33,34,35,36,37,38)$, social $(39,40,41,42,43,44)$. The response options and scoring remained similar (but not identical) to the original proposed by the author, Rebecca Oxford. That is to say, a graduated scale from 1 to 5, where: $1=$ Never, 2 =Almost never, $3=$ Frequently, 4 = Almost always, $5=$ Always. The adapted scale was written in English, since almost all students were proficient in that language, either as their native language or because they had learned it as L2. Other versions were also available, translated into other languages (German, Chinese and Portuguese), allowing learners to read and respond in their native language and avoiding misinterpretations. Background information, such as students' academic level, age and place of origin was provided by the mentioned institutions, the respective teachers and the students, through short conversations and topic questions in the inventory. A data matrix was built with the Statistical Package for Social Sciences (SPSS), where each item was entered as an empirical variable. The reliability analysis was implemented through Cronbach's alpha coefficient, which revealed that the scale used had an acceptable degree of reliability, with a value of 0.865 , obtained through SPSS. The validity was achieved by removing the low significance items (less than 0.3 ) from the item-total correlations table, only if it produced a significant increase in the alpha coefficient and according to the criteria of the researcher when the variable was considered important.

The statistical descriptive analysis was conducted for each strategy use (44) and category (memory, cognitive, metacognitive, affective and social). In this process, the arithmetic mean $M$ was used as a measure of central tendency to describe the data set, and standard deviation $S D$ was used as a measure of variability or dispersion. The frequency distribution was very useful to characterize and understand the data.

\section{RESUlts}

\subsection{Statistics and data analysis basis}

Oxford (1990) refers to the arithmetic mean $M$ as an indicator of the strategy use, considering the range of levels that follows:

- High: If the mean takes any value between 3.5 and 5;

- Medium: If the mean takes any value between 2.5 and 3.4;

- Low: If the mean takes any value between 1 and 2.4.

The same consideration was adopted and applied in this study. The use of each kind of strategy is represented by its mean value in Table 1 (see Appendix).

\subsection{Memory strategies use}

In this group, composed by nine strategies, there is a predominance of medium use values (56\%) and only one high value corresponding to the strategy 1 ("I think of relationships between what I already know and new things I learn in Spanish"). Furthermore, this 
strategy has the lowest standard deviation value of the group $(M=4, S D=0.79)$, which indicates it is the most representative. Only 1 student reported almost never using it, but no one reported never using it.

Strategies 2, 3, 4, 8 and 9 have very similar mean values, but some differences in standard deviation. Strategies 5, 6 and 7 show low levels of use. As can be seen in their respective frequency distribution, these strategies accumulate great values $(71 \%, 62 \%$ and $71 \%$ respectively) of students that never or almost never use these strategies. The few individuals who almost always report using the strategy 5 ("I use rhymes to remember new words") are all Chinese. It seems that the majority does not make use of actions or physical elements like flashcards to memorize, but prefer to review the lessons or to use the new words to remember them.

\subsection{Cognitive strategies use}

In this group, there is a distribution represented by $64 \%$ higher mean values and $36 \%$ medium values, with no low value registered. Strategy 11 ("I try to talk like native Spanish speakers") tops the list with the highest mean and the lowest standard deviation, with no one never using it. Strategies 12, 14, 19 and 20 are gathered with similar mean values. Strategies 19 and 20 present a remarkable similarity in their frequency distributions. Strategies 13, 21 and 22 share great similarities in their frequency distribution and mean values as well. Strategies $10,13,15,17,18$ and 22 show very similar mean values. Strategies 16 ("I read for pleasure in Spanish") and 23 ("I make summaries of information that I hear or read in Spanish") deviate slightly from the others and they rank at the bottom with the lowest values of the group. In both, there are numerous cases in which students report never using them (14.5\% and $23 \%$ respectively). It is noteworthy that 12 of the 13 subjects from the United States frequently use the strategy 23.

\subsection{Metacognitive strategies use}

In this group there is a majority of high values ( $78 \%$ of strategies) and only two strategies reach the medium level of use (no low values registered). The mean values and the standard deviations are distributed similarly among the strategies, except for the strategies 28 and 30. Strategy 26 was notable due to its high value with $88.4 \%$ of students who report almost always and frequently use it. Strategies 27 and 32 are very similar in mean value, $S D$ and frequency distributions. Moreover, the percentages of students who report almost always and frequently using it are quite high ( $74 \%$ and $77 \%$ respectively). In relation to strategy 28 ("I plan my schedule so I will have enough time to study Spanish") a large percentage of subjects (22\%) report never or almost never using it. None of these individuals are Chinese; instead, this nationality reaches high values for this strategy, followed by English-speaking individuals mainly from the United States.

\subsection{Affective strategies use}

This group is quite heterogeneous in arithmetic mean values and there are no significant similarities in frequency distribution between the strategies. Values are distributed in high, 
medium and low by three equal parts. Strategy 34 ("I encourage myself to speak Spanish even when I am afraid of making a mistake") tops the list with a mean value $M=3.9$ and $74 \%$ of subjects who reported frequently and almost always using it, while an $11.5 \%$ reported never or almost never use it. Strategy 37 ("I write down my feelings in a language learning diary") is at the bottom of the table with a low level of use $(M=1.5)$. The few individuals who reported using it always and almost always are women from the United States, Germany and Australia. It must be noted that 3 of 4 subjects who report frequently using it are Chinese males. The rest of the group (88\%) report never or almost never using it.

\subsection{Social strategies use}

In this group there is a set of strategies with high values at $100 \%$. Strategy 44 ("I try to learn about the culture of Spanish speaker") has the highest value supported by $85.5 \%$ of the sample who reported always or almost always using it. However, there are two individuals who report never using it. In all other strategies in this group, the subjects generally report almost always using them, so the histograms are quite similar, except for the strategy 41 ("I practice Spanish with other students"). There are 17 subjects (1 Chinese and 16 from other countries) who almost always use this strategy. Chinese students seem not to use strategy 43 ("I ask questions in Spanish"), contrarily to students from other nationalities.

\subsection{Strategy use by category}

Mean values were calculated for each category and their corresponding standard deviations, expressed in Table 2. Social strategies are the most common among the study group $(M=4.1)$, with the least dispersion level $(S D=0.98)$. They are followed by metacognitive $(M=3.7)$ and cognitive $(M=3.5)$ strategies. Finally, the affective and mnemonic categories obtain the same mean value $(M=2.8)$.

Table 2. Mean scores and standard deviations for each strategy category

\begin{tabular}{lcc}
\hline \multicolumn{1}{c}{ Category } & $M$ & SD \\
\hline Social & 4.1 & 0.98 \\
Metacognitive & 3.7 & 0.99 \\
Cognitive & 3.5 & 1.17 \\
Affective & 2.8 & 1.15 \\
Memory & 2.8 & 1.2 \\
\hline
\end{tabular}

\section{Conclusion}

The empirical work was conducted in three different academic settings. A quite heterogeneous sample was considered, in terms of Spanish proficiency, age, cultural profile, and places of origin which reach up to ten countries around the world. The use of an in- 
strument for data collection (Language Learning Strategy Inventory) that has already been developed, used and assessed in numerous and significant studies in all continents has been an advantage. However, none of these studies has excluded the compensatory strategies, as we have done in this work. In this sense, I decided to keep the theoretical difference that arises between communication strategies and learning strategies. The reliability and validity analysis determined that the instrument used is reliable as well as stable and consistent in its measurements. Through this, an effective translation of concepts into variables can produce the same results in other possible tests.

Memory strategies seem to be the least used. This is likely because these strategies are almost unknown to the students or because they have never used them before, for example the use of flashcards, rhymes, or acting the words out to memorize. Interestingly, most students think of relationships between what they already know and new things they learn in Spanish, which shows the implementation of previously acquired skills, probably in other languages. The association of a word with its image and the situations in which it could be used is a key factor in learning a second language since it involves the creation of mental images (also through hand-illustrated images), through which new information is linked to the information already stored in the mind. These representations can be worked with iconic, mental or graphic figures, so they can be intuitively acquired by learners of a language to a very significant degree. Reviewing the lessons is especially useful for memorizing and remembering new information, and it seems to be often used, mainly by Chinese students who are more likely to use this strategy.

With regards to cognitive strategies, some results are worth mentioning. Making summaries of heard or read information in Spanish is the least used strategy in this category, which consists of summarizing the original text in order to grasp the main ideas. There is a high probability that this particular strategy strongly depends on cultural background and student's educational system of origin. As a matter of fact, $92 \%$ of students who frequently use it are from the United States. Despite its importance, 23\% of students reported never using it. Another aspect worthy of attention in relation to this category is the huge similarity in frequency distributions which is not seen in any other category. Saying or writing new Spanish words is almost always used by Chinese students. This may be due to the great difference between the Chinese and Spanish alphabetic and phonetic systems. The same considerations can be assumed for the strategy of practicing the sounds of Spanish, for which Chinese students are friendly users. Finding patterns in Spanish seems not to be welcomed by males, as they all reported never or almost never using it. Strategies like writing notes, messages, letters, or reports in Spanish could be linked to the proficiency level, since almost all Chinese individuals (the students with lowest level) report never or almost never making use of them.

Metacognitive strategies are the pillars of the organization, planning and evaluation of the learning process. The entire study sample frequently performed actions related to these operations. The fact that $88 \%$ of foreign students almost always and frequently pay attention when someone speaks Spanish indicates both that there is a strong interest in learning and that the subjects are active, which are basic requirements for learning. The basis of organization and planning includes "looking for people to talk to in Spanish", "looking for opportunities to read as much as possible" and "having clear goals for improving skills and planning the 
schedule to study". With regards to the aforementioned strategy, only $22 \%$ students plan time for studying. Assessment, a substantial fact in the learning process, is represented by trying to discover how to be a better learner, thinking about learning progress, noticing mistakes and using that information to improve. All of these strategies are very similar in use scores and some of them nearly have the same frequency distribution, possibly due to the essence underlying all of them: self-awareness and self-assessment.

Affective strategies, as well as memory strategies, had the lowest mean values among categories. This is perhaps due to the fact that this group of strategies is the most difficult to practice and teach, as they involve the affective and emotional aspects of learning. The affective component is characterized by being more stable and durable, while the emotional component refers to an intense mood condition that can be transient, pleasant or painful, generally associated to somatic aspects. The actions that help to assess the feelings, motivations, attitudes and to control emotions mainly consist of three strategies: "I notice if I am tense or nervous when I am studying or using Spanish", "I talk to someone else about how I feel when I am learning Spanish" and "I write down my feelings in a language learning diary". Unless students know how they feel and why, they will not have advantages in controlling the emotional side. The use of a language learning diary proves to be the least used of the 44 strategies (88\% report never or almost never use it) and it seems to be preferred by Western women, while Chinese men also use it. Self-reward is rarely used in general, but seems to be welcomed by Chinese students. Encouraging oneself to speak Spanish when afraid of making a mistake is highly used. However one of four individuals (25\%) is never or almost never encouraged, which is not a negligible amount. It is a teacher's responsibility to lead students to raise awareness of the nature of the error and include it as an active, natural and necessary factor in the learning process, with no major concerns, inhibitions or shame. It is also a teacher's task to control the class in order to avoid teasing or uncomfortable situations among the students, which can negatively affect a student.

Social strategies deserve a great consideration. In order to properly understand this section, it is helpful to review the fundamental aspect of the communicative approach: the main aim in language teaching is the development of communicative competence. Communicative competence, in turn, is composed by a number of subcompetences (Canale \& Swain, 1980), including sociolinguistic competence; therefore this category should be strongly considered in language teaching. "Sociolinguistic competence is concerned with knowledge and skills required to deal with the social dimension of language use" (Council of Europe, 2001:118). It includes linguistic markers of social relations, politeness conventions, expressions of folkwisdom, register differences; dialect and accent. In a communicative situation, the context becomes highly important and it is culturally determined, since the complete contextual meaning is provided by the culture. Foreign language learning cannot be understood without considering the cultural component, since the suitability of a communicative action is given by socially defined factors such as beliefs, attitudes, symbols, assumptions, etc. It is remarkable that students already have incorporated these criteria, as it is shown in the fact that $85.5 \%$ of the sample report always or almost always trying to learn the culture of Spanish speakers. The other social strategies are aimed to establish communicative interaction, the maximum expression of cultural component interrelationships. It is possible to infer that this subset of strategies depends greatly on the level of the student, however it should be 
determined under statistical analysis. As it was mentioned before, Chinese students who were beginners in their proficiency of the language, rarely asked questions in Spanish or practiced with other students.

The proposed objectives in this research were successfully achieved, since the strategies and categories used were identified. Likewise, the study determined which ones were most or least frequently used by students.

We live in an increasingly populated world and it becomes necessary to create mechanisms of tolerance and socio-cultural acceptance. Language learning is a way to partially understand these issues and it could contribute to a peaceful and intelligent coexistence in the noosphere. Moreover, language learning implies the existence of strategies that can be learned and applied in different situations in order to optimize learning and to allow autonomy in this continuous process of lifelong learning.

The results of this study brought to light some general aspects of language learning strategies use and showed some other specific aspects, for example the great similarities in frequency distribution and mean values in some strategies and the preference of certain types of strategies according to nationality or gender. These results are preliminary, but they are in accordance with other studies mentioned before. Thus, this could lead to hypothesize on the possible relationships between LLS and multiple factors (endogenous and exogenous) which should be deeply analyzed under statistical protocols. Future specific researches in these topics could help significantly in the teaching field, by allowing a precise and optimal planning of learning strategies, according to each particular situation.

\section{REFERENCES}

Canale, M., and Swain, M. (1980). "Theoretical bases of communicative approaches to second language teaching and testing", in Applied linguistics, 1: 1-47.

Cohen, A. (2011). "L2 learner strategies", in E. Hinkel (ed.), Handbook of research in second language teaching and learning. New York: Heinle, 681-698.

Corbetta, P. (2007). Metodología y ténicas de la investigación social. Madrid: McGRAW-HILL.

Council of Europe. (2001). Common European Framework of Reference for Languages: Learning, Teaching, Assessment. Strasburg.

Dörnyei, Z. (2005). The Psychology of the language learner. Individual differences in second language acquisition. Londres: Lawrence Erlbaum Associates.

Green, J. M., and Oxford, R. (1995). "A Closer Look at Learning Strategies, L2 Proficiency, and Gender”, in TESOL Quarterly, 29 (2): 261-297.

Griffiths, C. (2003). Language learning strategy use and proficiency (Doctoral dissertation, University of Auckland). Available from http://hdl.handle.net/2292/9, accessed 11 November, 2012.

Instituto Cervantes. (2006). Enciclopedia del español en el mundo. Madrid: Instituto CervantesPlaza y Janés.

Moreno, F., and Roth, J. O. (2007). Atlas de la Lengua Española en el Mundo. Barcelona: Ariel.

O’Malley, J. M., and Chamot, A. U. (1990). Learning Strategies in Second Language. Cambridge: Cambridge University Press.

Oxford, R. (1990). Language learning strategies: what every teacher should know. New York: Newbury House. 
Oxford, R. (2011). Teaching and researching language learning strategies. Harlow: Pearson Education.

Rahimi, M., Riazi, A., and Saif, S. (2008). "An investigation into the factors affecting the use of language learning strategies by Persian EFL learners", in Canadian Journal of Applied Linguistics (CJAL), 11(2): 31-60.

Roncel Vega, V. M. (2002). Proyecto de investigación educativa. Escala sobre las estrategias de aprendizaje en una lengua extranjera. Sevilla: I.E.S. Al-Ándalus de Arahal.

Selinker, L. (1972). "La interlengua", in J. M. Liceras (ed.), La adquisición de las lenguas extranjeras. Madrid: Visor, 79-97.

Tarone, E. (1981). "Some thoughts on the notion of communication strategy", in TESOL Quarterly, 15(3): 285-295.

\section{Appendix}

Table 1. Mean scores and standard deviations for each strategy use

\begin{tabular}{lcc}
\hline \multicolumn{1}{c}{ STRATEGY } & $M$ & $S D$ \\
\hline $\begin{array}{l}\text { 1. I think of relationships between what I already know and new things I } \\
\text { learn in Spanish. }\end{array}$ & 3.97 & 0.79 \\
2. I use new Spanish words in a sentence so I can remember them. & 3.28 & 1.06 \\
3. I connect the sound of a new Spanish word and an image or picture of & 2.96 & 1.34 \\
the word to help me remember the word. & & \\
4. I remember a new Spanish word by making a mental picture of a situation & 2.97 & 1.24 \\
in which the word might be used. & 1.94 & 1.12 \\
5. I use rhymes to remember new Spanish words. & 2.19 & 1.45 \\
6. I use flashcards to remember new Spanish words. & 2.06 & 1.19 \\
7. I physically act out new Spanish words. & 2.91 & 1.17 \\
8. I review Spanish lessons often. & 2.90 & 1.48 \\
9. I remember new Spanish words or phrases by remembering their location & & 1.25 \\
on the page, on the board, or on a street sign. & 3.45 & 1.25 \\
10. I say or write new Spanish words several times. & 4.25 & 0.85 \\
11. I try to talk like native Spanish speakers. & 3.77 & 1.14 \\
12. I practice the sounds of Spanish. & 3.57 & 1.06 \\
13. I use the Spanish words I know in different ways. & 3.87 & 1.10 \\
14. I start conversations in Spanish. & 3.52 & 1.34 \\
15. I watch Spanish language TV shows spoken in Spanish or go to movies & & \\
spoken in Spanish. & 3.01 & 1.30 \\
16. I read for pleasure in Spanish. & 3.42 & 1.30 \\
17. I write notes, messages, letters, or reports in Spanish. & 3.50 & 1.27 \\
18. I first skim a Spanish passage then go back and read carefully. & 3.91 & 1.09 \\
19. I look for words in my own language that are similar to new words & & \\
in Spanish. & & \\
\hline
\end{tabular}




\begin{tabular}{lll}
\hline \multicolumn{1}{c}{ STRATEGY } & $M$ & $S D$ \\
\hline 20. I try to find patterns in Spanish. & 3.8 & 1.21 \\
21. I find the meaning of a Spanish word by dividing it into parts that I & 3.23 & 1.14 \\
understand. & 3.50 & 1.05 \\
22. I try not to translate word-for-word. & 2.65 & 1.27 \\
23. I make summaries of information that I hear or read in Spanish. & 3.83 & 0.91 \\
24. I try to find as many ways as I can to use my Spanish. & 3.75 & 1.03 \\
25. I notice my Spanish mistakes and use that information to help me do better. & 4.29 & 0.71 \\
26. I pay attention when someone is speaking Spanish. & 4.03 & 0.98 \\
27. I try to find out how to be a better learner of Spanish. & 3.09 & 1.05 \\
28. I plan my schedule so I will have enough time to study Spanish. & 3.75 & 1.14 \\
29. I look for people I can talk to in Spanish. & 3.25 & 1.16 \\
30. I look for opportunities to read as much as possible in Spanish. & 3.64 & 1.01 \\
31. I have clear goals for improving my Spanish skills. & 4.09 & 0.94 \\
32. I think about my progress in learning Spanish. & 3.50 & 1.15 \\
33. I try to relax whenever I feel afraid of using Spanish. & & 1.00 \\
34. I encourage myself to speak Spanish even when I am afraid of making & 3.91 & \\
a mistake. & 2.04 & 1.14 \\
35. I give myself a reward or treat when I do well in Spanish. & 2.91 & 1.29 \\
36. I notice if I am tense or nervous when I am studying or using Spanish. & 1.48 & 0.99 \\
37. I write down my feelings in a language learning diary. & 4.12 & 0.98 \\
38. I talk to someone else about how I feel when I am learning Spanish. & 3.00 & 1.31 \\
39. If I do not understand something in Spanish, I ask the other person to & 4.09 & 1.00 \\
slow down or say it again. & 3.96 & 1.12 \\
40. I ask Spanish speakers to correct me when I talk. & 3.64 & 1.07 \\
41. I practice Spanish with other students. & 4.26 & 0.83 \\
42. I ask for help from Spanish speakers. & 4.91 \\
43. I ask questions in Spanish. & & \\
44. I try to learn about the culture of Spanish speakers. & & \\
\hline
\end{tabular}

